\title{
Effect of breviscapine injection on clinical parameters in diabetic nephropathy: A meta-analysis of randomized controlled trials
}

\author{
XIAODAN LIU, LI YAO, DA SUN, XINWANG ZHU, QIANG LIU, TIANHUA XU and LINING WANG
}

Department of Nephrology, The First Affiliated Hospital, China Medical University, Shenyang, Liaoning 110001, P.R. China

Received January 21, 2015; Accepted January 28, 2016

DOI: $10.3892 /$ etm.2016.3483

\begin{abstract}
Diabetic nephropathy (DN) is currently a major public health problem worldwide. The objective of the present study was to evaluate the clinical effect of breviscapine injections in patients with DN. A meta-analysis was performed using the following databases to obtain published reports in any language: PubMed/MEDLINE, Embase, China National Knowledge Infrastructure, Chinese Evidence-Based Medicine, Wanfang Digital Periodicals, Chinese Academic Journals Full-text Database, Chinese Biological and Medical Database, China Doctoral and Masters Dissertations Full-text Database and the Chinese Proceedings of Conference Full-text Database. Two assessors independently reviewed each trial. A total of 35 randomized controlled trials, which performed studies on a total of 2,320 patients (1,188 in treatment groups and 1,132 in control groups), were included in the present meta-analysis. Data were analyzed using Stata version 11.0 for Windows. The results from the analysis demonstrated that breviscapine injections have greater therapeutic effects in patients with DN in comparison with the control group, including renal protective effects (reducing urine protein, serum creatinine and blood urea nitrogen) and adjustment for dyslipidemia (affecting levels of cholesterol, triglycerides and high density lipoproteins). These effects indicate that breviscapine injections are beneficial to patients with DN. Further studies are required to determine the mechanisms underlying the therapeutic effects of breviscapine.
\end{abstract}

\section{Introduction}

Diabetic nephropathy (DN) is a progressive disease with an increasing prevalence in developed and developing countries, and has a significant impact on morbidity and mortality from chronic kidney disease (CKD), end-stage renal disease

Correspondence to: Professor Lining Wang, Department of Nephrology, The First Affiliated Hospital, China Medical University, 155 Nanjing North Street, Shenyang, Liaoning 110001, P.R. China E-mail: wanglining5623@gmail.com

Key words: breviscapine, diabetic nephropathy, urine protein, renal function, blood fat
(ESRD) and cardiovascular disease (1-3). Although significant progress has been made in understanding the pathogenesis of DN, the current treatments for diabetic kidney disease only provide partial therapeutic effects; more effective therapies for $\mathrm{DN}$ are required (4).

Erigeron breviscapus (Vant.) Hand.-Mazz. is a native plant species of Yunnan, China. Breviscapine, as a purified flavonoid extract from this species, was first isolated by Zhang et al (5). Breviscapine primarily contains two flavonoids, namely scutellarin and apigenin-7-O- $\beta$-glucoside. Scutellarin accounts for $\sim 90 \%$ of the extract; apigenin-7-O- $\beta$-glucoside accounts for $\sim 4 \%$ (6).

Breviscapine has a broad range of pharmacological effects, including dilation of micro-blood vessels, reduction of blood viscosity and improvement of the microcirculation; it also has an anti-platelet, anti-thrombotic action and can decrease plasma fibrin content and promote fibrinolytic activity $(7,8)$. Since the 1970s, breviscapine injections have been extensively used in China for the treatment of ischemic cardiovascular and cerebrovascular diseases, such as angina pectoris, myocardial infarction and focal cerebral infarction $(9,10)$.

Breviscapine has been demonstrated to possess a number of pharmacological functions in addition to its hemodynamic effects; it has been reported to serve as an anti-oxidative stress agent and a protein kinase $\mathrm{C}(\mathrm{PKC})$ inhibitor, and can improve renal function and reduce urinary micro-albuminuria, suggesting that this drug has great therapeutic potential for the treatment of DN $(11,12)$. Although a number of clinical trials have investigated the renal protection provided by breviscapine in DN, uncertainties remain regarding the efficacy of breviscapine. This is primarily a result of the lack of high-quality, large-sample randomized clinical trials. The purpose of the present study was to systematically review randomized control trials (RCTs) and explore the effect of breviscapine in DN.

\section{Materials and methods}

Study design. All the RCTs that were identified to investigate the effect of breviscapine on DN were included. There was no restriction on the language or year of publication.

Subject criteria. Each patient included in the analysis fulfilled the definition of diabetic mellitus $(13,14)$. Patients with DN in stages III-IV according to the DN diagnostic criteria of Mogensen et al (15) were included in the study. Patients with 
chronic diseases [chronic liver disease, chronic respiratory disease, heart failure, cerebrovascular disease, malignant tumors, serious hypertension, autoimmune disease, acute diabetic complications (for example, diabetic ketoacidosis), hyperglycemic hyperosmolar status], infectious diseases, organ transplants or a recent history of the application of nephrotoxic drugs, were excluded from the study.

Data extraction and appraisal of methodological quality. A standard data extraction method was performed independently by two authors, and the following information from each eligible study was recorded: Study design, participant characteristics [age, gender, history of diabetes mellitus (DM), number of patients in the breviscapine group and the control group], therapeutic intervention [basic treatment including diet control, the control of blood glucose, antihyperlipidemics, antihypertensives, angiotensin-converting enzyme inhibitor (ACEI) and angiotensin receptor blocker (ARB), and treatment duration]. Whether these parameters were comparable between the breviscapine treatment group and the control group was assessed.

An intravenous drip of breviscapine was administered to the patients in the treatment group. The commercial injection fluid (sourced from numerous companies across these studies) was produced from extracted flavonoids of Erigeron breviscapus (Vant) Hand.-Mazz., and was manufactured in accordance with the quality standards of the Chinese State Drug Administration. Each patient in the treatment groups received the same type of injection using the same standards; the dosage ranged from 20 to $100 \mathrm{mg} / \mathrm{day}$, and the studies had a treatment duration of between 2 weeks and 1 month.

Therapeutic effect criteria included 24-h urine protein levels, urinary albumin excretion rate, renal function [serum creatinine (SCr) and blood urea nitrogen (BUN) levels], and levels of cholesterol, triglycerides, high density lipoproteins (HDL) and fibrinogen.

Search strategy. A systematic literature search was performed to identify studies concerning the treatment of patients with DN using breviscapine. MEDLINE/PubMed, Embase, the China National Knowledge Infrastructure (CNKI) Database, Chinese Evidence-Based Medicine Database (CEBM), Wanfang Digital Periodicals Database (WFDP), Chinese Journal Full-text Database (CJFD), Chinese Biological and Medical Database (CBM), China Doctoral and Masters Dissertations Full-text Database and the Chinese Proceedings of Conference Full-text Database were searched. Reference lists from the relevant studies were examined to identify further studies and previous reviews of the field. Articles citing the aforementioned studies were examined to identify additional relevant studies.

Assessment methodology. All articles that were identified in the database search were screened by two authors independently, and disagreements were resolved by consensus. Missing data from trials were obtained from the principal investigators of the relevant studies, if possible. The studies were graded for methodological quality according to the Jadad scale (16). A study was considered high quality if graded with $\geq 3$ scores on the Jadad scale.
Statistical analysis. A meta-analysis was conducted using Stata version 11.0 for Windows (StataCorp LP, College Station, TX, USA). The principal measure of effect was the weighted mean difference (WMD) between the breviscapine and control groups, and the standardized mean difference (SMD) was used when analyzing 24 -h urine protein as this is a continuous variable with large differences in mean. The confidence interval (CI) was $95 \%$, as the outcome measurements were the same for each analysis. Heterogeneity was assessed using a $\chi^{2}$ test $(\mathrm{P}<0.1$ was considered to indicate a statistically significant difference) and an $\mathrm{I}^{2}$ test $\left(\mathrm{I}^{2}>50 \%\right.$, significant heterogeneity; $\mathrm{I}^{2}<25 \%$, insignificant heterogeneity). Begg's test was used to assess publication bias.

\section{Results}

Study characteristics. A total of 126 publications were initially identified; 64 were excluded as they were not relevant to the study question. A total of 62 clinical trials were retrieved for detailed evaluation. Of these, 28 were excluded for the following reasons: No measurement data $(n=5)$, absence of a control group for comparison with the breviscapine group $(\mathrm{n}=1)$, patients were at clinical stage $\mathrm{V}$ of $\mathrm{DN}(\mathrm{n}=2)$, supplementing the breviscapine treatment with other, similar drugs $(\mathrm{n}=11)$, breviscapine was administered as a control drug $(\mathrm{n}=5)$, oral administration $(\mathrm{n}=1)$ and duplicate publication $(\mathrm{n}=2)$. Thus, 34 studies comprising 34 RCTs were eligible for inclusion in the present analysis $(11,17-50)$ These 34 RCTs are summarized in Tables I-III. A total of 2,260 patients were included (1,158 patients in treatment group and 1,102 patients in the control group). Each study was performed in China and all of the patients involved were Chinese.

24-h urine protein. A total of 25 clinical trials evaluated the 24-h urine protein in patients treated with breviscapine $(n=858)$ and the control group $(n=836)$. Fig. 1 presents a forest plot for the outcome measurements (SMD, $-1.42 ; 95 \%$ CI, -1.83 to -1.02). In comparison with the control group, breviscapine significantly reduced 24 -h urine protein in patients with DN $(\mathrm{P}<0.001)$.

Urinary albumin excretion rate. A total of 9 clinical trials evaluated the urinary albumin excretion rate in patients treated with breviscapine $(n=291)$ and the control group $(\mathrm{n}=264)$. Fig. 2 presents a forest plot for the outcome measurements (WMD, -23.16 ; 95\% CI, -37.20 to -9.12). In comparison with the control group, breviscapine significantly reduced the urinary albumin excretion rate in patients with $\mathrm{DN}(\mathrm{P}<0.001)$.

SCr expression levels. A total of 21 clinical trials evaluated the expression level of $\mathrm{SCr}$ in patients treated with breviscapine $(n=711)$ and the control group $(n=689)$. Fig. 3 presents a forest plot for the outcome measurements (WMD, -12.50; 95\% CI, -18.16 to -6.84). In comparison with the control group, breviscapine significantly reduced the expression level of $\mathrm{SCr}$ in patients with $\mathrm{DN}(\mathrm{P}<0.001)$.

BUN expression levels. A total of 16 clinical trials evaluated the expression level of BUN in patients treated with breviscapine $(n=594)$ and the control group $(n=572)$. Fig. 4 presents 


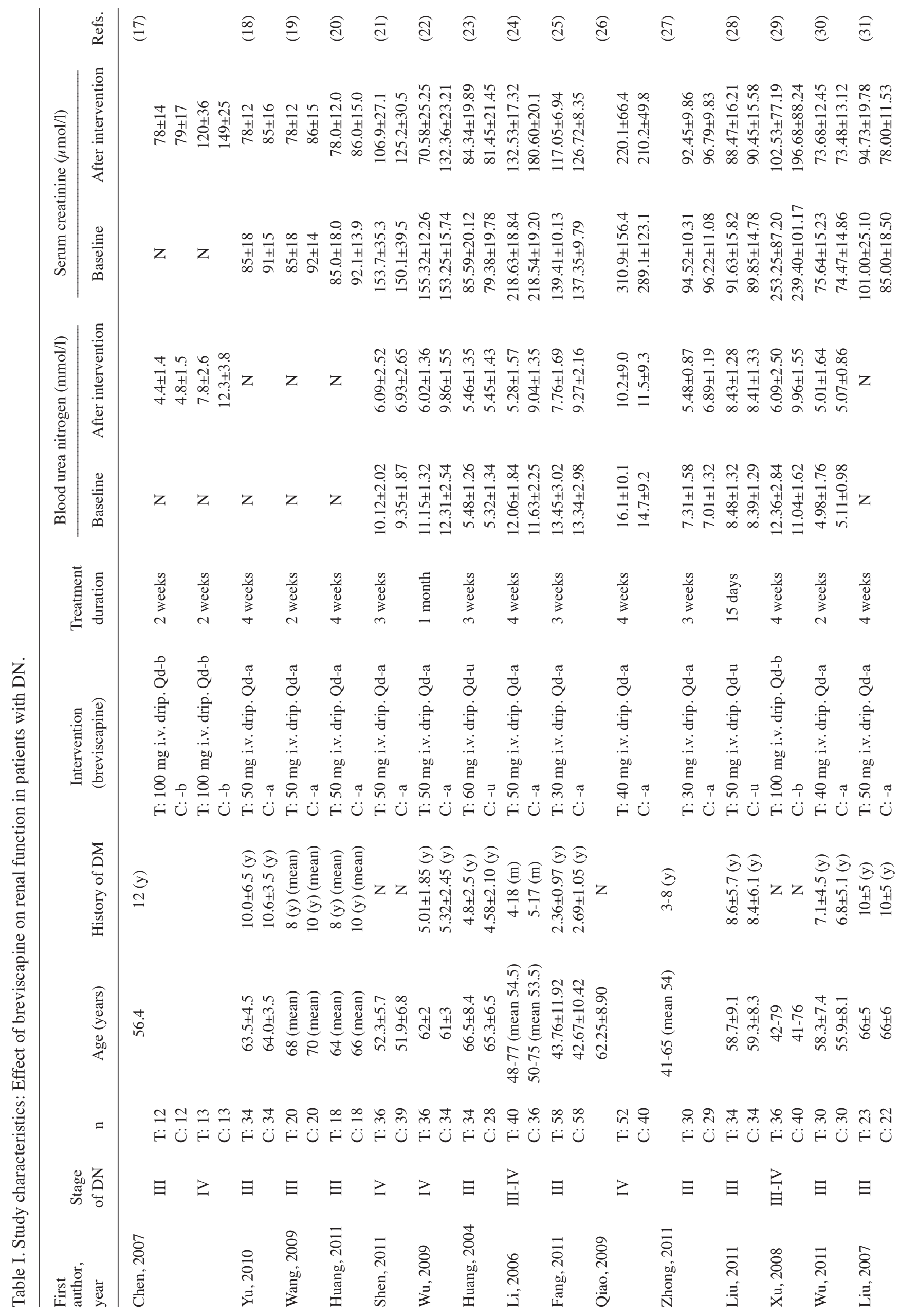




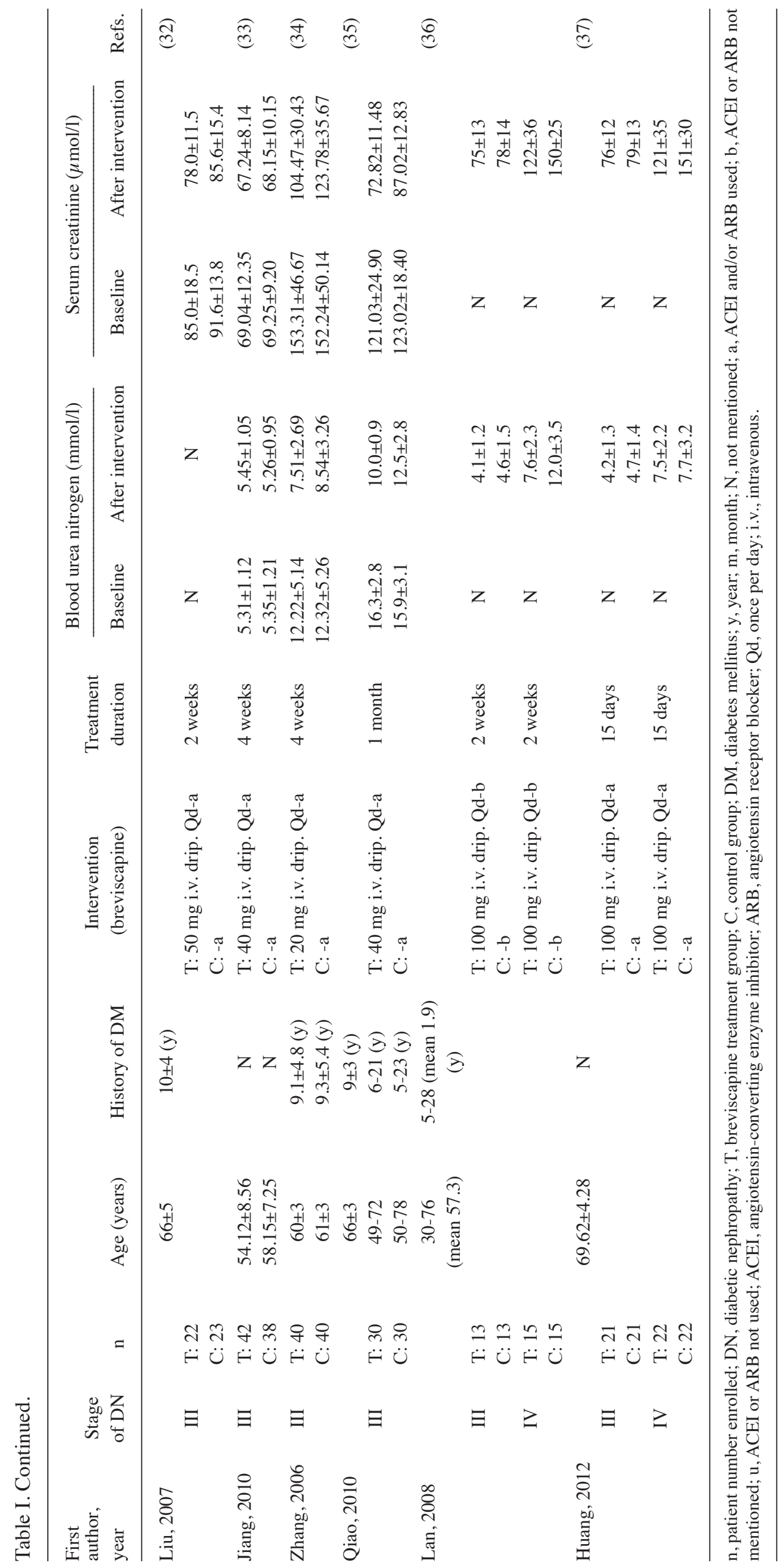




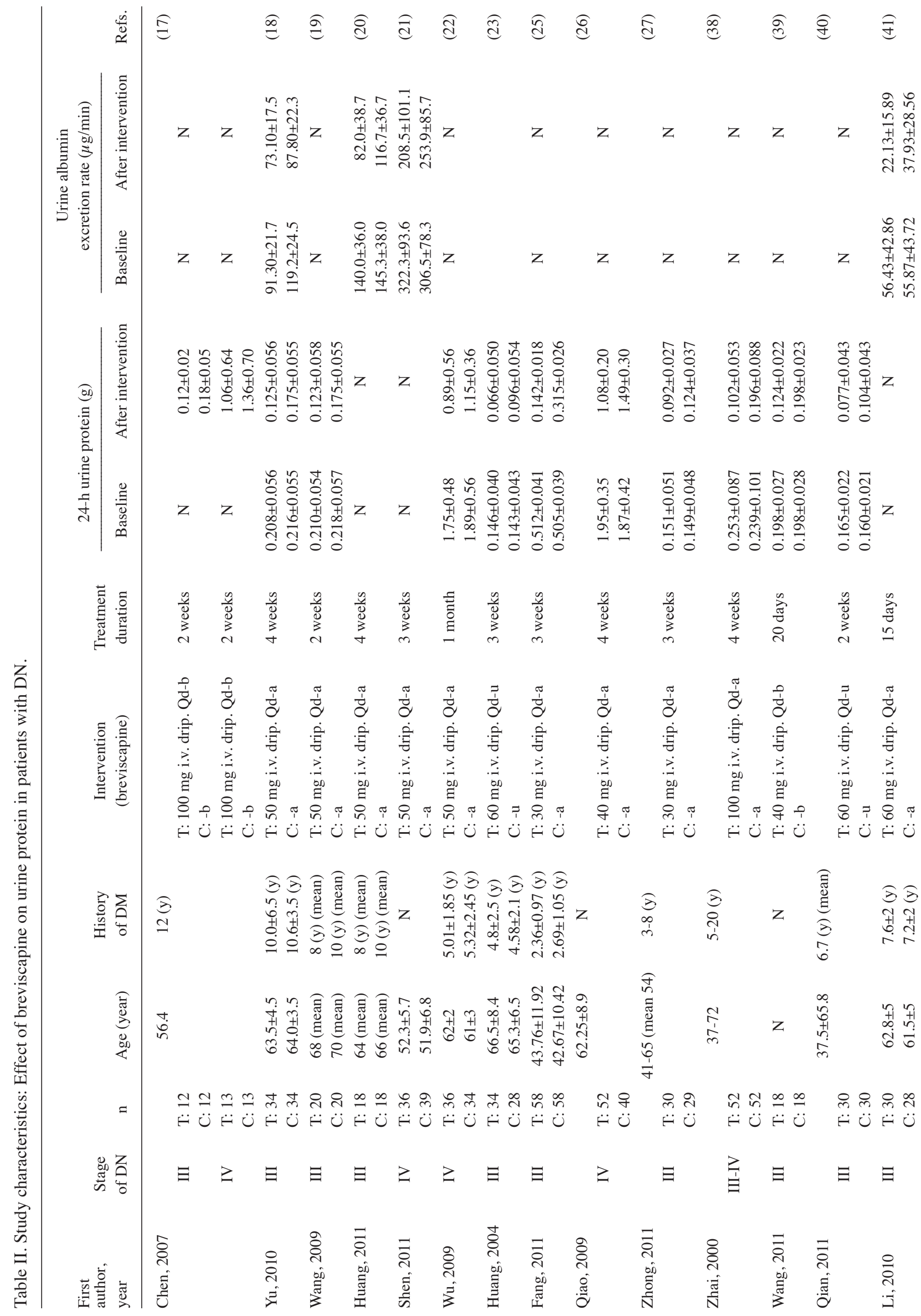




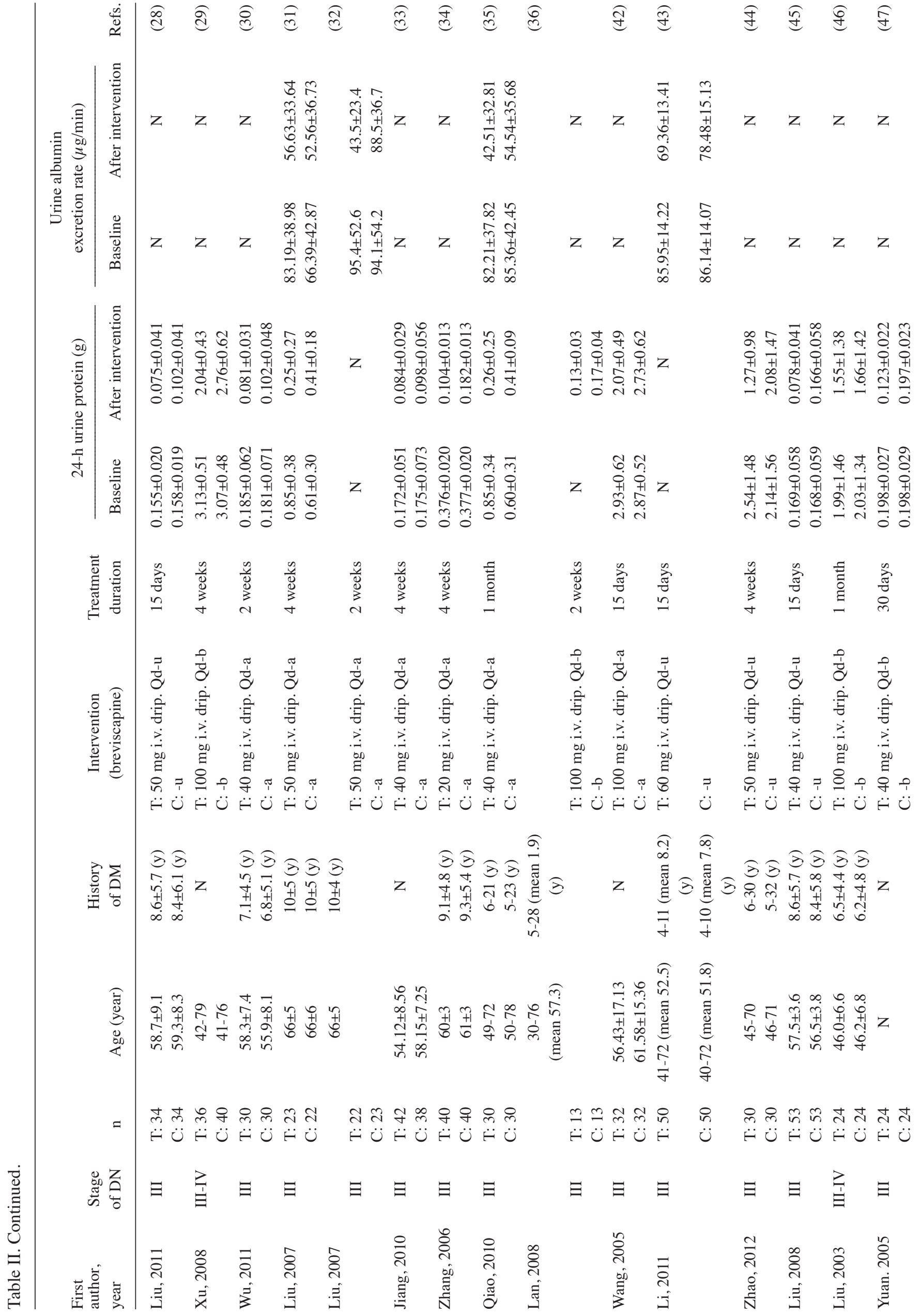


a forest plot for the outcome measurements (WMD, -1.52; 95\% CI, -2.25 to -0.78). In comparison with the control group, breviscapine significantly reduced the expression level of BUN in patients with $\mathrm{DN}(\mathrm{P}<0.001)$.

Cholesterol expression levels. A total of 12 clinical trials evaluated the expression level of cholesterol in patients treated with breviscapine $(n=394)$ and the control group $(n=351)$. Fig. 5 presents a forest plot for the outcome measurements (WMD, $-0.67 ; 95 \% \mathrm{CI},-1.12$ to -0.22 ). In comparison with the control group, breviscapine significantly reduced the expression level of cholesterol in patients with $\mathrm{DN}(\mathrm{P}<0.001)$.

Triglyceride expression levels. A total of 15 clinical trials evaluated the expression level of triglycerides in patients treated with breviscapine $(\mathrm{n}=472)$ and the control group $(\mathrm{n}=428)$. Fig. 6 presents a forest plot for the outcome measurements (WMD, $-0.52 ; 95 \% \mathrm{CI},-0.72$ to -0.33 ). In comparison with the control group, breviscapine significantly reduced the expression level of triglycerides in patients with $\mathrm{DN}(\mathrm{P}<0.001)$.

HDL expression levels. A total of 5 clinical trials evaluated the expression level of HDL in patients treated with breviscapine $(\mathrm{n}=172)$ and the control group $(\mathrm{n}=132)$. Fig. 7 presents a forest plot for the outcome measurements (WMD, 1.57; 95\% CI, 0.47 to 2.67). In comparison with the control group, breviscapine significantly increased the expression level of high density lipoproteins in patients with $\mathrm{DN}(\mathrm{P}<0.001)$.

Fibrinogen expression levels. A total of 9 clinical trials evaluated the expression level of fibrinogen in patients treated with breviscapine $(n=296)$ and the control group $(n=261)$. Fig. 8 presents a forest plot for the outcome measurements (WMD, $-1.25 ; 95 \%$ CI, -1.56 to -0.93). In comparison with the control group, breviscapine significantly reduced the expression level of fibrinogen in patients with $\mathrm{DN}(\mathrm{P}<0.001)$.

Adverse effects. No systematic review on adverse effects was conducted as reporting of side effects was lacking in the clinical trials in this meta-analysis.

Publication bias assessment. The Begg's test determined that bias assessment was not significant in any of the RCTs analyzed $(\mathrm{P}>0.1)$.

\section{Discussion}

The prevalence of DM has markedly increased in recent years and is projected to affect $4.4 \%$ of the world's population by 2030 (51). DN is considered to be the most devastating complication associated with diabetes, with respect to a patients' quality of life and chances of survival (52). Current treatments are not adequate, and as the burden of DN continues to increase worldwide there is a requirement for the development of novel treatments (53).

Oxidative stress caused by increased free radical production is understood to serve a central role in the development of DN (54). The abnormal metabolism of glucose or free fatty acids via mitochondria pathways, and the activation of nicotinamide adenine dinucleotide phosphate oxidases 


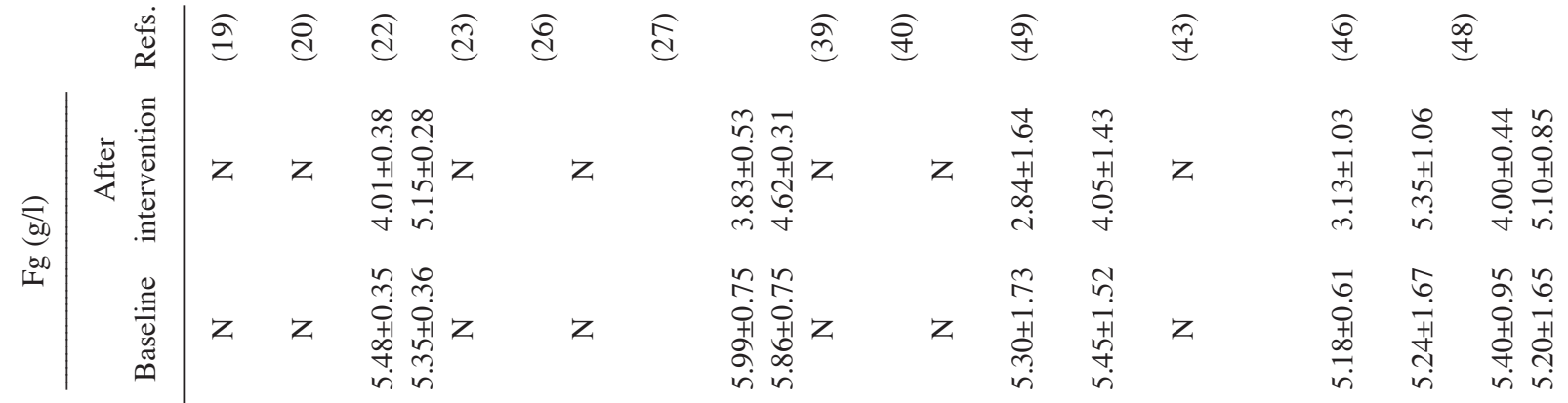

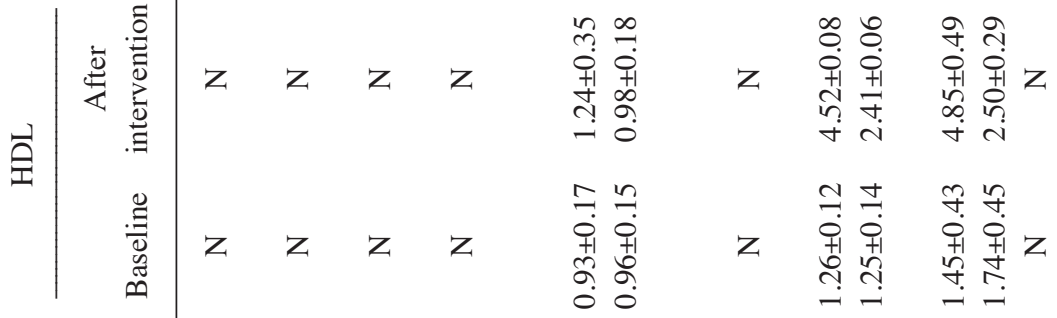

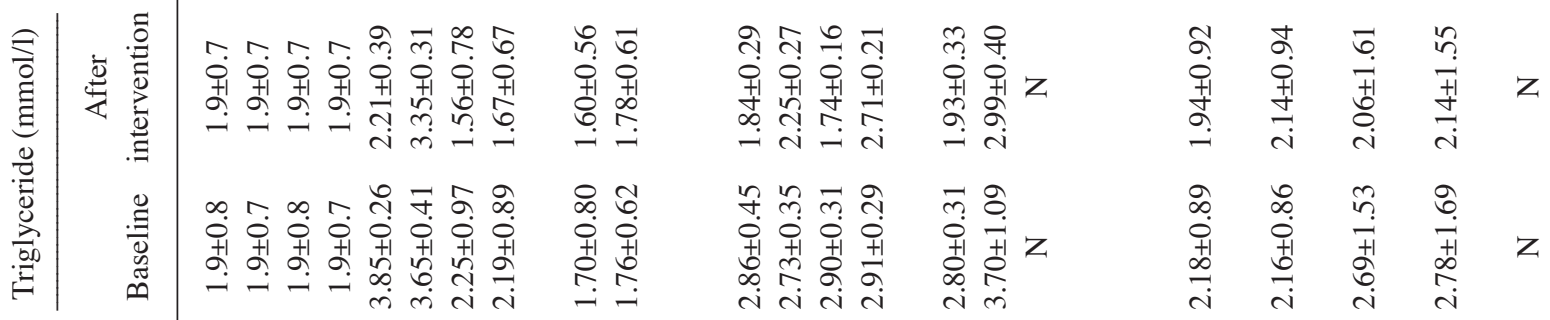

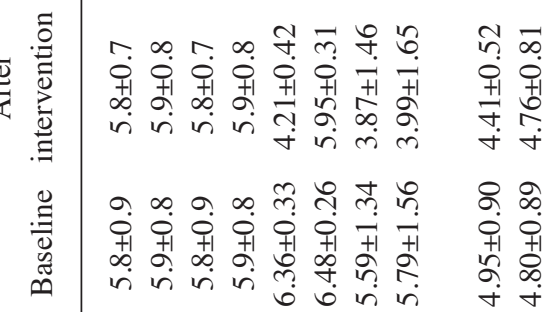

莺 氧

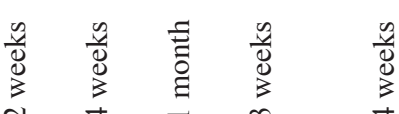

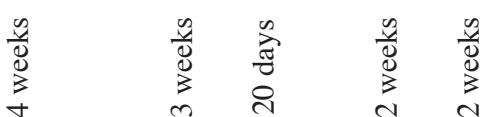

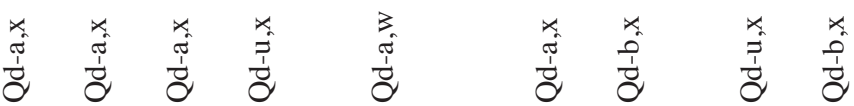

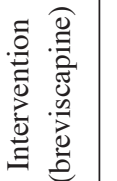

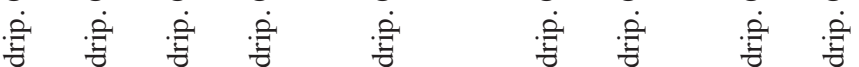

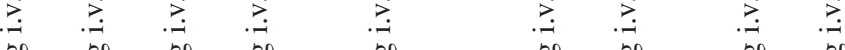

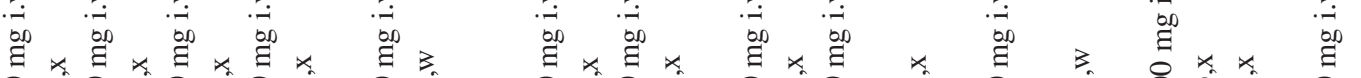

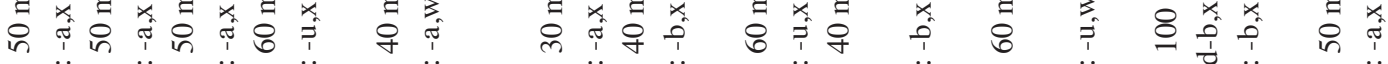
$\ddot{H} \ddot{U} \ddot{H} \ddot{U} \ddot{\sim} \ddot{U} \ddot{\sim}$ $\ddot{H} \ddot{U}$

$\ddot{H} \ddot{\sim} \ddot{\sim} \ddot{U} \ddot{H} \ddot{U} \ddot{H}$

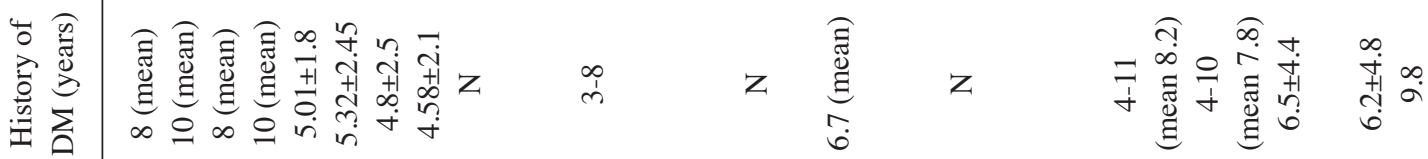

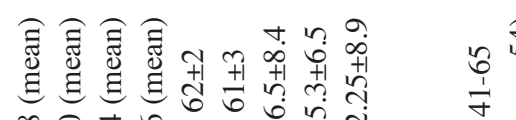
$\infty$ ₹

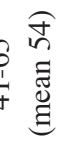

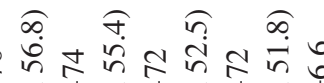

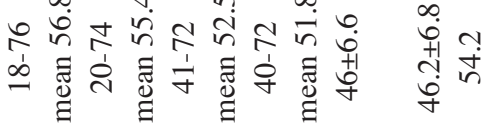

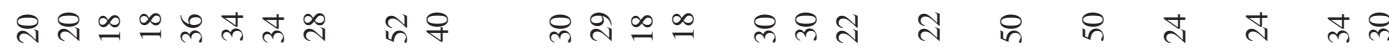

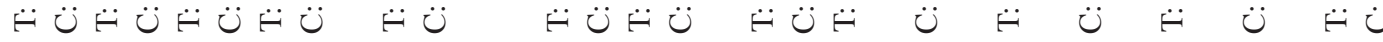

总台台 


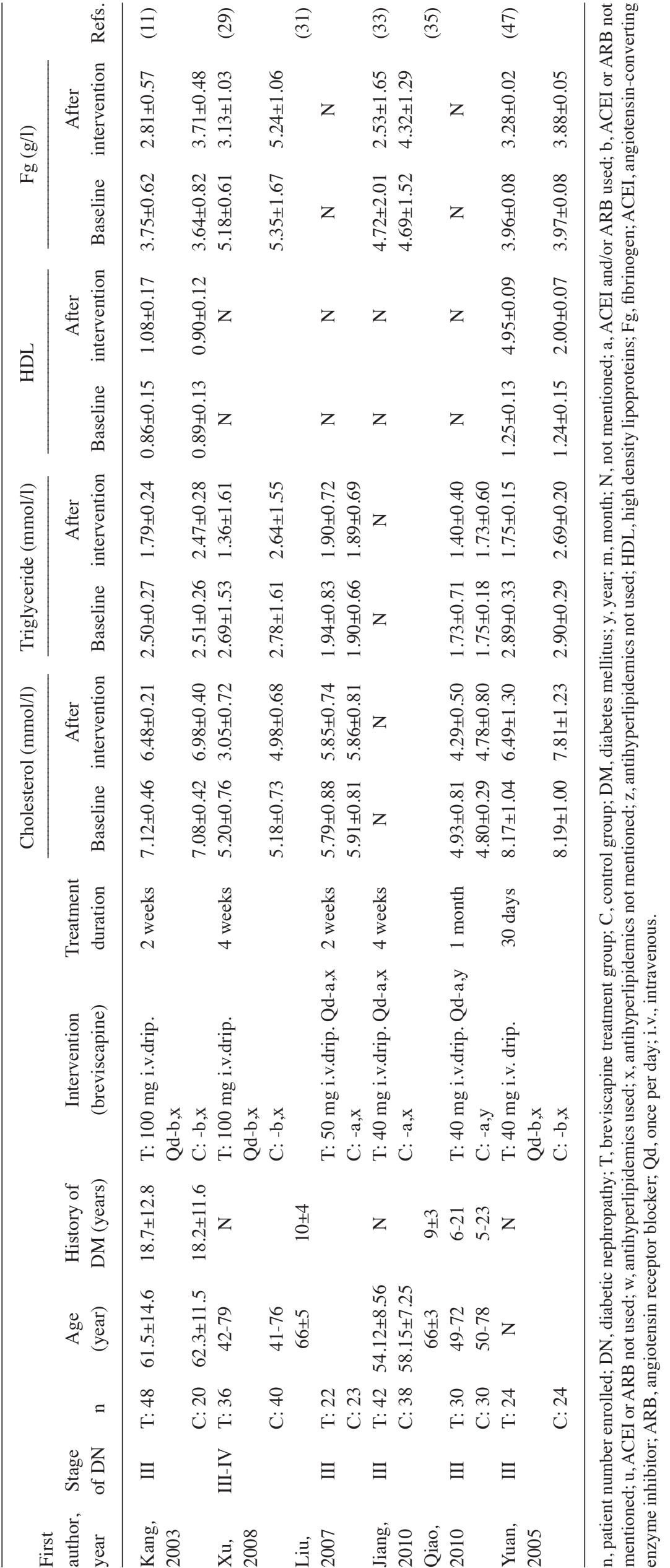




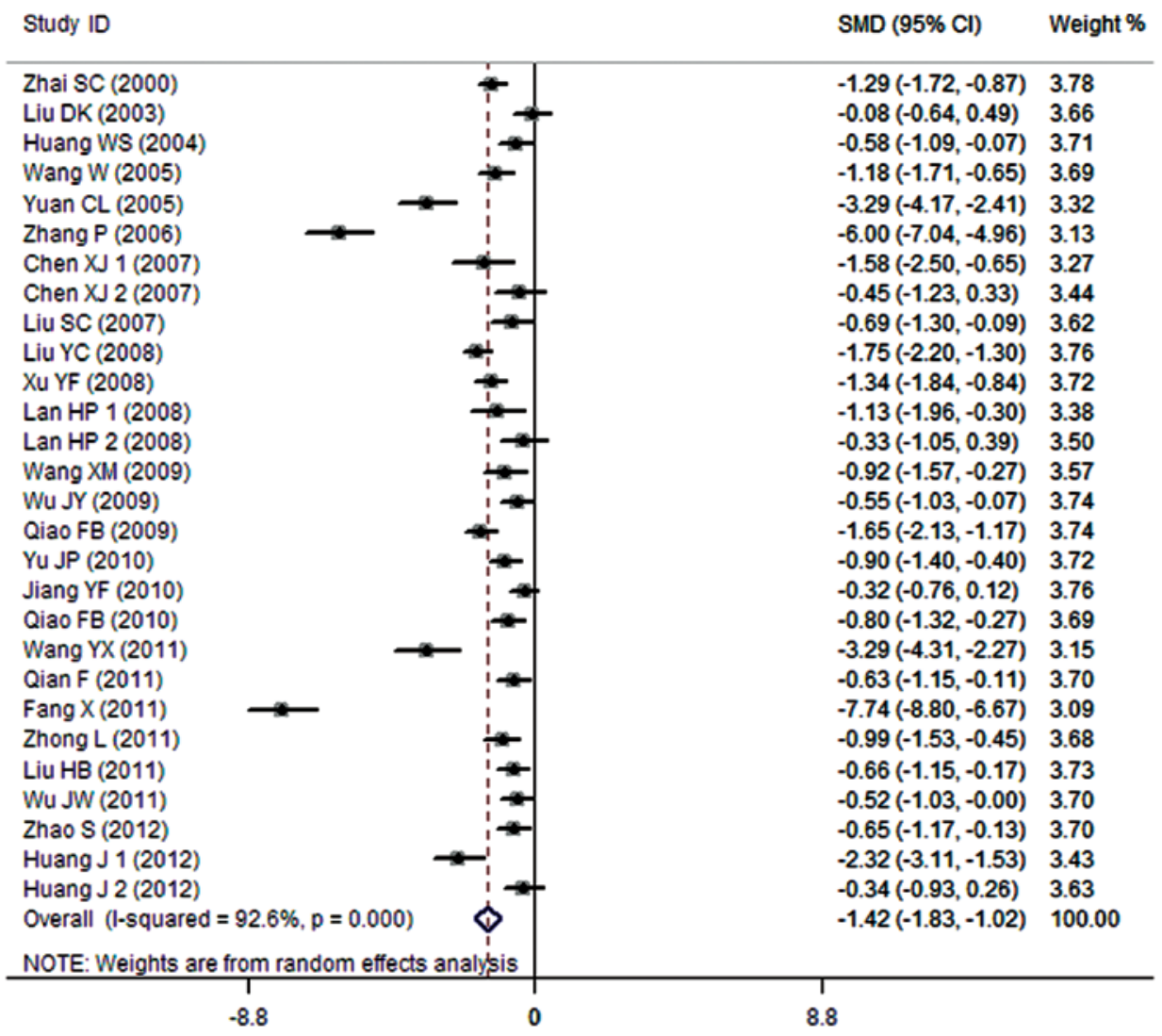

Figure 1. Effect of breviscapine on 24-h urine protein in patients with diabetic nephropathy. ID, identification; SMD, standardized mean difference; CI, confidence interval.

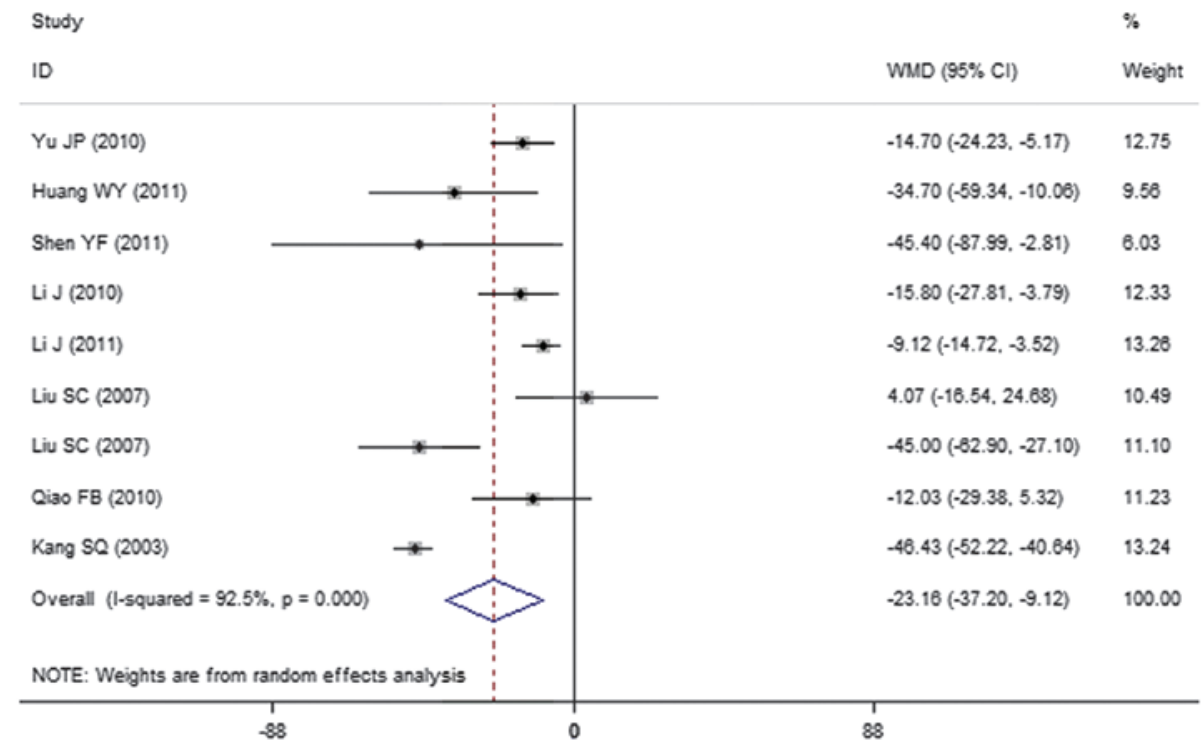

Figure 2. Effect of breviscapine on urine albumin excretion rate in patients with diabetic nephropathy. ID, identification; WMD, weighted mean difference; CI, confidence interval.

via PKC have been recognized as contributors towards the production of oxidants (55). Breviscapine possesses a variety of pharmacological functions other than hemodynamic effects, and can serve as an anti-oxidative stress agent and inhibitor of PKC $(56,57)$. In addition, Zhao et al (58) and Wagener et al (59) observed in diabetic rat models that breviscapine can inhibit podocyte apoptosis by modulating the expression of B-cell lymphoma 2 (Bcl-2) and Bcl-2-Associated X Protein genes.

The present meta-analysis quantitatively evaluated the clinical effect of breviscapine in the treatment of patients with DN by integrating the outcomes of $35 \mathrm{RCT}$ s that studied the effects of breviscapine on 1,188 patients with DN and 1,132 control subjects. The results demonstrated that the expression levels of 


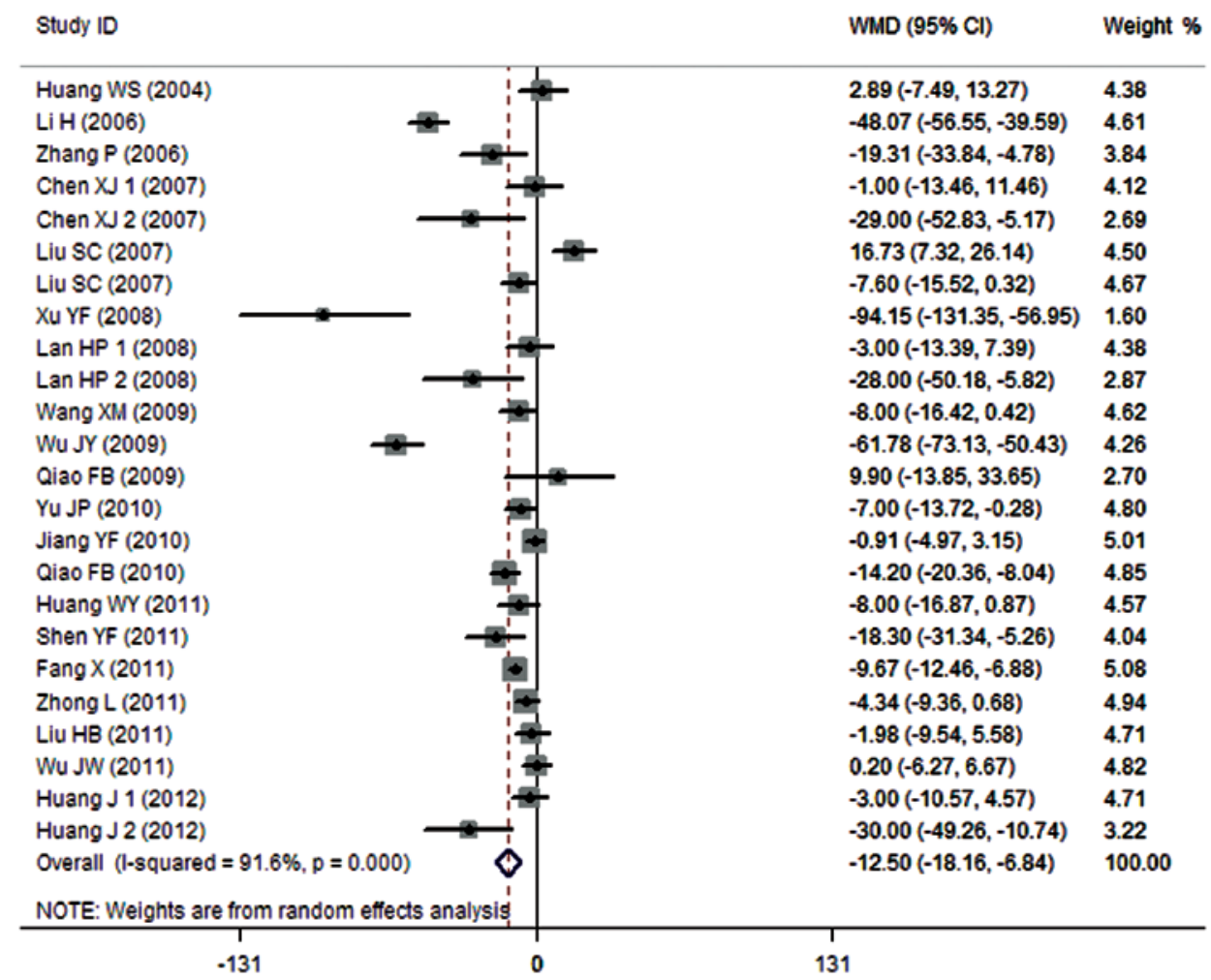

Figure 3. Effect of breviscapine on serum creatinine in patients with diabetic nephropathy. ID, identification; WMD, weighted mean difference; CI, confidence interval.

\begin{tabular}{|c|c|c|}
\hline Study ID & WMD $(95 \% \mathrm{Cl})$ & Weight \% \\
\hline Huang WS (2004) & $0.01(-0.69,0.71)$ & 5.84 \\
\hline LiH (2006) & $-3.76(-4.42,-3.10)$ & 5.87 \\
\hline Zhang P (2006) & $-1.03(-2.34,0.28)$ & 5.15 \\
\hline Chen XJ1 (2007) & $-0.40(-1.56,0.76)$ & 5.34 \\
\hline Chen XJ2 (2007) & $-4.50(-7.00,-2.00)$ & 3.59 \\
\hline Xu YF (2008) & $-3.87(-4.82,-2.92)$ & 5.59 \\
\hline Lan HP1 (2008) & $-0.50(-1.54,0.54)$ & 5.48 \\
\hline Lan HP2 (2008) & $-4.40(-6.52,-2.28)$ & 4.07 \\
\hline Wu JY (2009) & $-3.84(-4.52,-3.16)$ & 5.85 \\
\hline Qiao FB (2009) & $-1.30(-5.08,2.48)$ & 2.34 \\
\hline Jiang YF (2010) & $0.19(-0.25,0.63)$ & 6.03 \\
\hline Qiao FB (2010) & $-2.50(-3.55,-1.45)$ & 5.47 \\
\hline Shen YF (2011) & $-0.84(-2.01,0.33)$ & 5.33 \\
\hline Fang X (2011) & $-1.51(-2.22,-0.80)$ & 5.83 \\
\hline Zhong L (2011) & $-1.41(-1.94,-0.88)$ & 5.97 \\
\hline Liu HB (2011) & $0.02(-0.60,0.64)$ & 5.90 \\
\hline Wu JW (2011) & $-0.06(-0.72,0.60)$ & 5.87 \\
\hline Huang J1 (2012) & $-0.50(-1.32,0.32)$ & 5.73 \\
\hline Huang J2 (2012) & $-0.20(-1.82,1.42)$ & 4.74 \\
\hline Overall (1-squared $=92.9 \%, p=0.000$ ) & $-1.52(-2.25,-0.78)$ & 100.00 \\
\hline \multicolumn{3}{|l|}{ NOTE: Weights are from random effects analysis } \\
\hline $\begin{array}{l}1 \\
-7\end{array}$ & & \\
\hline
\end{tabular}

Figure 4. Effect of breviscapine on blood urea nitrogen in patients with diabetic nephropathy. ID, identification; WMD, weighted mean difference; CI, confidence interval.

SCr and BUN were significantly lower in patients treated with breviscapine in comparison with control subjects, suggesting that the drug serves a protective role in the renal system of patients with DN.
Microalbuminuria is regarded as the earliest clinical sign of DN. It is defined as a urinary albumin excretion rate ranging from $30-300 \mathrm{mg} / \mathrm{day}$, and the definitive measurement is based on a timed urine collection during a $24-\mathrm{h}$ period (60). The 


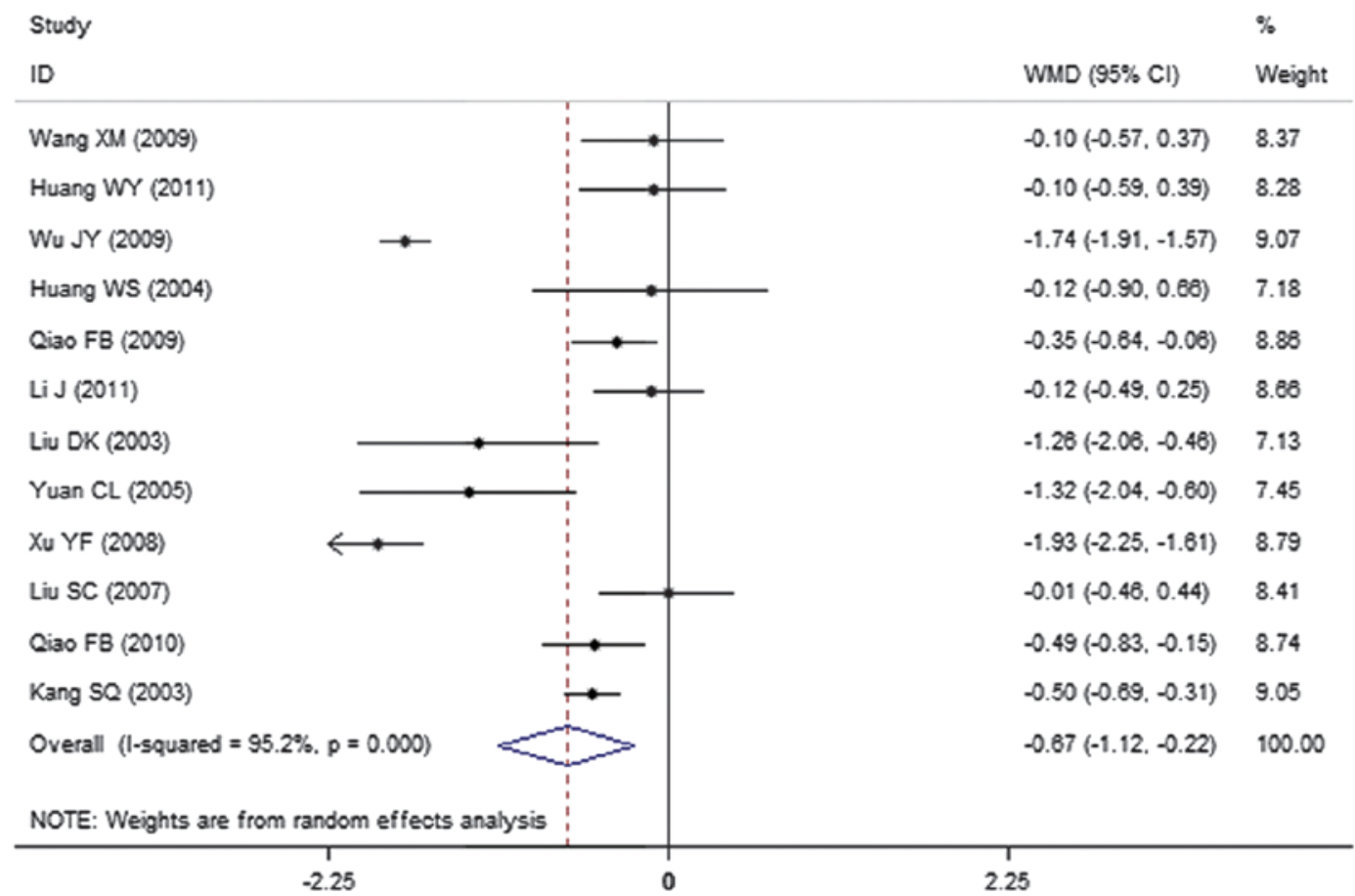

Figure 5. Effect of breviscapine on cholesterol in patients with diabetic nephropathy. ID, identification; WMD, weighted mean difference; CI, confidence interval.

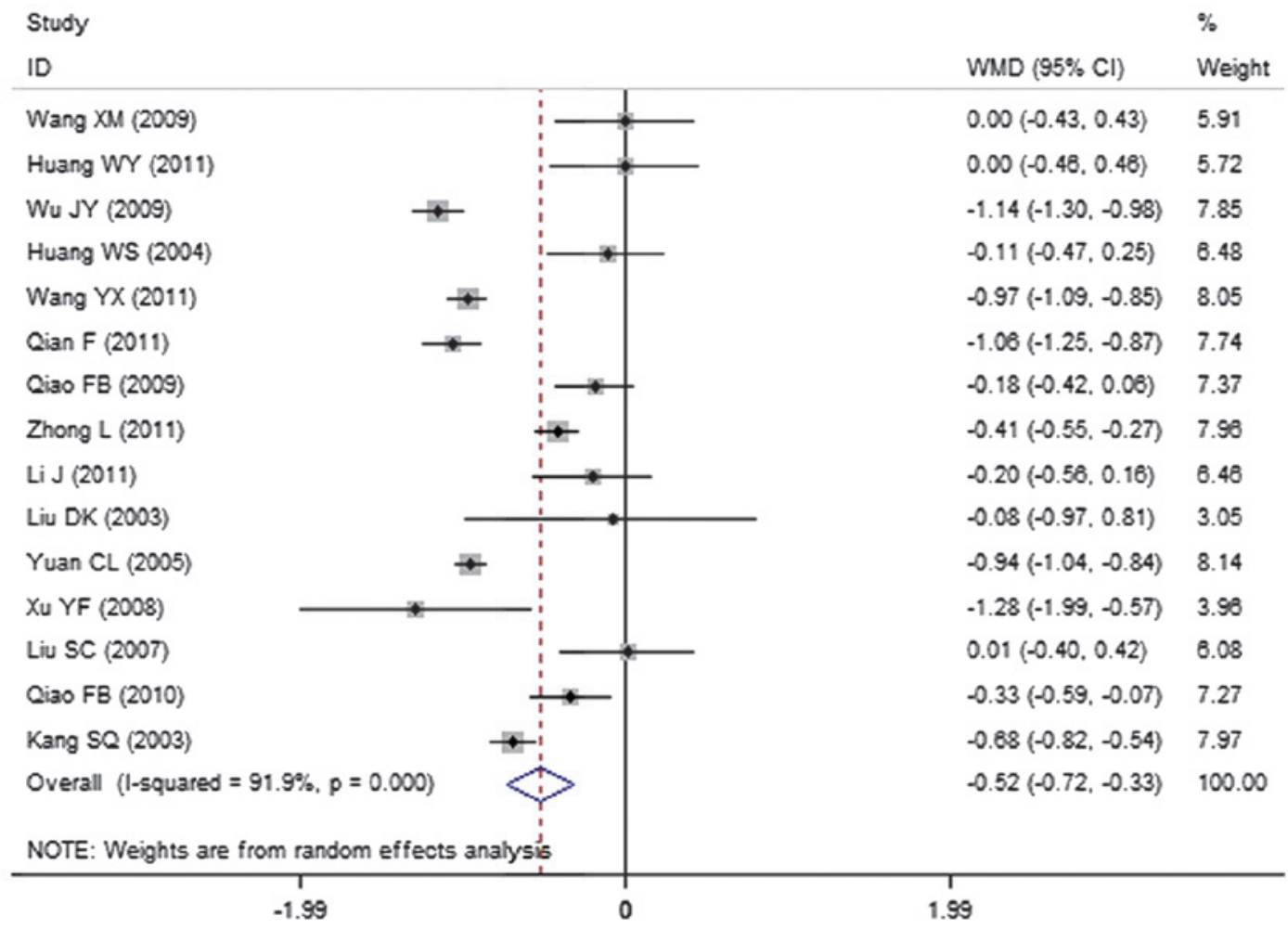

Figure 6. Effect of breviscapine on triglyceride in patients with diabetic nephropathy. ID, identification; WMD, weighted mean difference; CI, confidence interval.

present meta-analysis indicated that breviscapine can reduce urinary protein levels, with a reduction in 24-h urine protein values and the urinary albumin excretion rate; a reduction in urinary protein may contribute towards the renal protective effect of breviscapine in patients with DN.
There is evidence that dyslipidemia serves an important role in the progression of kidney disease in patients with diabetes (61). Dyslipidemia in diabetes is a condition that results in hypertriglyceridemia, low high-density lipoprotein levels, and increased small and low-density lipoprotein 


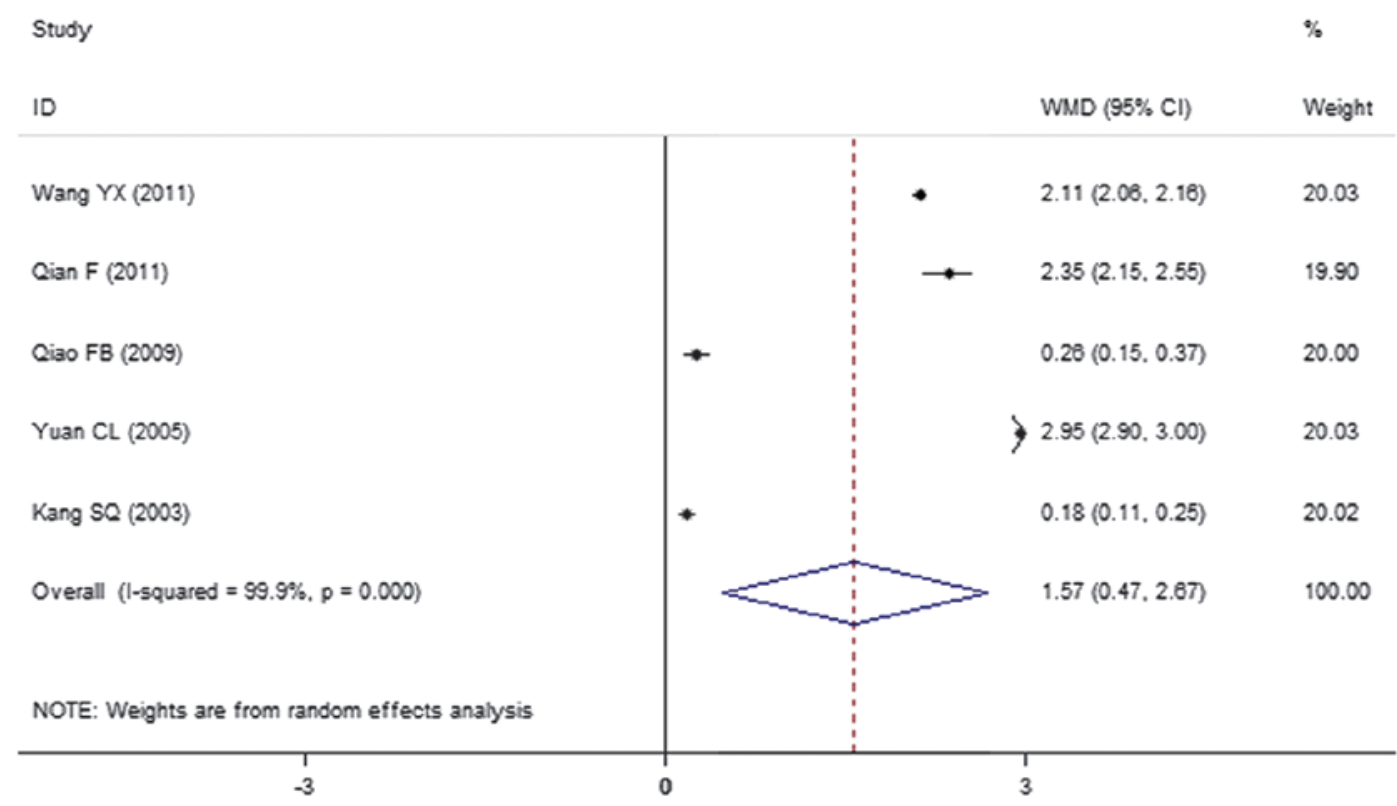

Figure 7. Effect of breviscapine on high density lipoproteins in patients with diabetic nephropathy. ID, identification; WMD, weighted mean difference; CI, confidence interval.

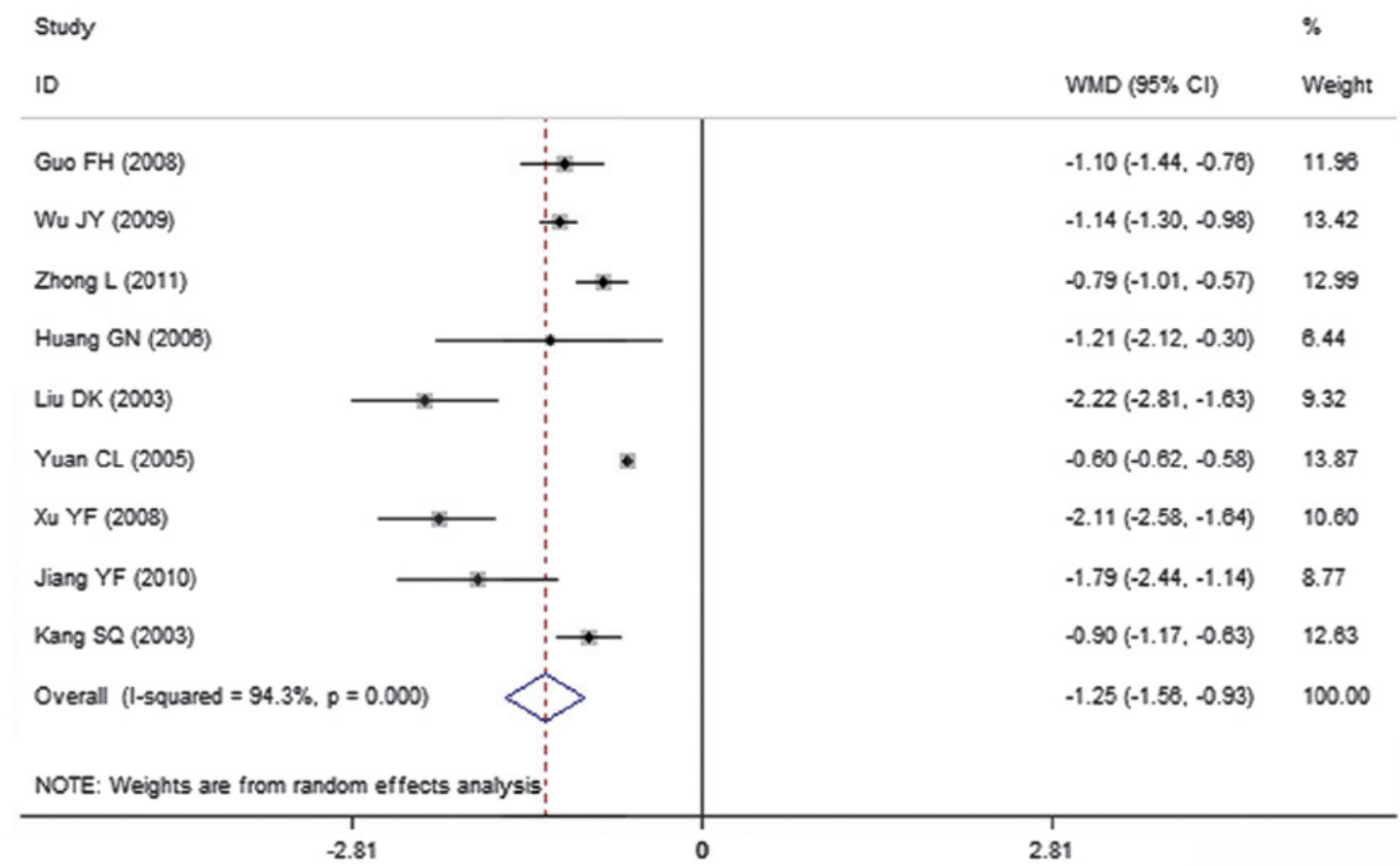

Figure 8. Effect of breviscapine on fibrinogen in patients with diabetic nephropathy. ID, identification; WMD, weighted mean difference; CI, confidence interval.

particles (62). Dyslipidemia is associated with the occurrence and progression of DN, and chronic kidney disease affects dyslipidemia (63). Lipids may cause glomerular and tubulointerstitial injury through mediators such as reactive oxygen species, cytokines and chemokines, and through hemodynamic changes (64). A number of trials have demonstrated that treating dyslipidemia not only decreased the risk of cardiovascular events, but also delayed the progression of DN (65). The present meta-analysis indicates that breviscapine reduces the levels of cholesterol and triglyceride, but increases the level of
HDL, in patients with DN; breviscapine is, therefore, capable of reversing dyslipidemia and protecting the renal system.

The present meta-analysis also demonstrated that breviscapine can reduce fibrinogen levels in patients with DN, which is in accordance with its function of promoting fibrinolytic activity, or may be related associated indirectly with the reduction of urine protein levels by breviscapine.

The protective effect of breviscapine is important with regard to the treatment of patients with $\mathrm{DN}$; breviscapine reduces urine protein, improves renal function and adjusts 
dyslipidemia. However, the present study explores only the clinical effect of breviscapine, and further studies are required to identify its underlying mechanisms. It is important to note that the majority of the RCTs analyzed in the present study were not of the highest quality; the toxicity of the drug was not thoroughly investigated and in a number of RCTs the lack of liver and kidney toxicity was discussed, but the associated data was not presented in detail. Further research is required that will adopt high quality methodology, including double-blind, multi-centered RCTs with large samples, and conduct long-term follow ups of patients treated with breviscapine in order to investigate its long-term safety.

\section{Acknowledgements}

The present study was supported by the Chinese Society of Nephrology (grant no. 13030320417).

\section{References}

1. Liu R, Zhong Y, Li X, Chen H, Jim B, Zhou MM, Chuang PY and He JC: Role of transcription factor acetylation in diabetic kidney disease. Diabetes 63: 2440-2453, 2014.

2. Lai X, Zhang AH, Chen SY, He L, Su CY, Fan MH and Wang T: Outcomes of stage 1-5 chronic kidney disease in Mainland China. Ren Fail 36: 520-525, 2014

3. Stanton RC: Frontiers in diabetic kidney disease: Introduction. Am J Kidney Dis 63 (2 Suppl 2): S1-S2, 2014.

4. Roscioni SS, Heerspink HJ and de Zeeuw D: The effect of RAAS blockade on the progression of diabetic nephropathy. Nat Rev Nephrol 10: 77-87, 2014.

5. Zhang RW, Zhang YL, Wang JS, Lin YY and Shang B: Isolation and identification of flavonoids from shortscape fleabane (Erigeron breviscapus). Zhong Cao Yao 19: 199-201, 1988 (In Chinese).

6. Wang M, Xie C, Cai RL, Li XH, Luo XZ and Qi Y: Studies on antioxidant activities of breviscapine in the cell-free system. Am J Chin Med 36: 1199-1207, 2008.

7. Wang M, Zhang WB, Zhu JH, Fu GS and Zhou BQ: Breviscapine ameliorates cardiac dysfunction and regulates the myocardial $\mathrm{Ca}(2+)$-cycling proteins in streptozotocin-induced diabetic rats. Acta Diabetol 47 (Suppl 1):S209-S218, 2010.

8. Jia JH, Chen KP, Chen SX, Liu KZ, Fan TL and Chen YC: Breviscapine, a traditional Chinese medicine, alleviates myocardial ischaemia reperfusion injury in diabetic rats. Acta Cardiol 63: 757-762, 2008.

9. Cao W, Liu W, Wu T, Zhong D and Liu G: Dengzhanhua preparations for acute cerebral infarction. Cochrane Database Syst Rev 4: CD005568, 2008.

10. He M, Xue ZM, Li J and Zhou BQ: Breviscapine inhibits high glucose-induced proliferation and migration of cultured vascular smooth muscle cells of rats via suppressing the ERK1/2 MAPK signaling pathway. Acta Pharmacol Sin 33: 606-614, 2012.

11. Kang SQ and Liu JY: Effect of breviscapine on urinary micro-albumine in patients with diabetes mellitus type 2 . Zhongguo Zhong Xi Yi Jie He Za Zhi 23: 458-459, 2003 (In Chinese).

12. Wei L and Tan J: Clinical observation on Breviscapine in treating hypertension patients complicated with micro-albuminuria of renal impairment. Chin J Integr Med 11: 31-33, 2005.

13. Definition, Diagnosis and Classification of Diabetes Mellitus and its Complications. World Health Organisation. 1999.

14. American Diabetes Association. Report of the expert committee on the diagnosis and classification of diabetes mellitus. Diabetes Care 7:1183-1197, 1997.

15. Mogensen CE, Christensen CK and Vittinghus E: The stages in diabetic renal disease. With emphasis on the stage of incipient diabetic nephropathy. Diabetes 32 (Suppl 2): 64-78, 1983.

16. Olivo SA, Macedo LG, Gadotti IC, Fuentes J, Stanton T, Magee DJ: Scales to assess the quality of randomized controlled trials: a systematic review. Phys Ther 88:156-175, 2008.

17. Chen XH: Clinical observation of therapy with Breviscapine for diabetic nephropathy. Zhongguo Liao Yang Yi Xue 16: 168-169, 2007 (In Chinese)
18. Yu JP: Breviscapine valsartan combined treatment of early diabetic nephropathy. Zhonghua Zhong Yi Yao Xue Kan 28: 1337-1338, 2010(In Chinese)

19. Wang XM: Impact of valsartan combined breviscapine trace urinary albumin in diabetic nephropathy and serum C-reactive protein. Lin Chuang He Li Yong Yao Za Zhi 2: 25-26, 2009 (In Chinese).

20. Huang WY: Observation of therapeutic effects with losartan and breviscapine on early diabetic nephropathy. Zhongguo Xiang Cun Yi Xue 18: 27-28, 2011 (In Chinese).

21. Shen YF and Dai Z: Clinical observation of therapy with candesartan and breviscapine on diabetic nephropathy. Zhongguo Shi Yong Yi Yao 6: 148-149, 2011(In Chinese).

22. Wu JY, Liang D, Ma ZH and Chen GH: Clinical observation of therapeutic effects with irbesartan and breviscapine on diabetic nephropathy. Guo Ji Yi Yao Wei Sheng Dao Bao 15: 53-55, 2009(In Chinese).

23. Huang WS and Sheng P: Clinical observation of therapy with breviscapine injection on early diabetic nephropathy. Dang Dai Yi Xue 10: 58-59, 2004(In Chinese).

24. Li H: Clinical observation of treatment effects with breviscapine injection and enalapril on 76 patients with diabetic nephropathy. Shi Yong Lin Chuang Yi Yao Za Zhi 10: 85-86, 2006 (In Chinese).

25. Fang X: Evaluation of therapeutic effects with breviscapine injection and enalapril on early diabetic nephropathy. Dang Dai Yi Xue 17: 131-132, 2011(In Chinese).

26. Qiao FB, Tian Z and He YL: Observation of treatment with breviscapine injection and benazepril on 52 cases with azotemia of diabetic nephropathy. Zhongguo Yao Ye 18: 55-56, 2009 (In Chinese).

27. Zhong L and Li K: Therapeutic effect of Breviscapine combined with Enalapril on early diabetic nephropathy. Hua Xi Yi Xue 26: 493-495, 2011 (In Chinese).

28. Liu HB, Liu CHa and Li XN: Observation of therapeutic effects with breviscapin on 68 cases with early diabetic nephropathy. Qingdao Yi Yao Wei Sheng 43: 41-42, 2011(In Chinese).

29. Xu YF and Yu JH: Clinical observation of treatment with breviscapin on 36 cases with diabetic nephropathy. Fu Jian Yi Yao Za Zhi 30: 133-134, 2008 (In Chinese).

30. Wu JW, Ling JH and Huang XN: Clinical observation of treatment with breviscapin and telmisartan on early diabetic nephropathy. Lin Chuang He Li Yongyao Za Zhi 4: 54-55, 2011(In Chinese).

31. Liu SC, Wen FG and Zhao CY: Clinical observation of treatment with breviscapin and lotensin on urinary protein of early diabetic nephropathy. Zhongguo Zhong Xi Yi Jie He Za Zhi 27: 530, 2007 (In Chinese).

32. Liu SC and Zhao CY: Protective effects of treatment with breviscapin and lotensin on early diabetic nephropathy. Guo Ji Zhong Yi Zhong Yao Za Zhi 29: 246-247, 2007 (In Chinese).

33. Jiang YF, He LQ and Shen LP: Clinical observation on therapeutic effects of combined use of dengzhanhuasu and losartan in treating early diabetic nephropathy. Liaoning Zhong Yi Xue Yuan Xue Bao 12: 43-45, 2010 (In Chinese).

34. Zhang P: Clinical observation on breviscapin combined with cozaar for diabetic nephropathy. Zhongguo Yao Fang 17: 1403-1404, 2006 (In Chinese).

35. Qiao FB, Li CT, Li LF, Zhang CJ, He QL and Ren LX: Clinical observation of treatment with breviscapine and candesartan on early diabetic nephropathy. Yi Nan Bing Za Zhi 9: 606-608, 2010(In Chinese).

36. Lan HP and Wu FQ: Clinical observation of treatment with breviscapine on diabetic nephropathy. Zhengjiang Lin Chuang Yi Xue 10: 389, 2008 (In Chinese).

37. Huang J, Wen Z and Feng Y: Clinical observation of treatment with breviscapine on diabetic nephropathy. Zhongguo Bao Jian Ying Yang 9: 3347-3348, 2012 (In Chinese).

38. Zhai SC: Analysis of treatment with breviscapine on diabetic nephropathy. Shandong Yi Yao 40: 69-70, 2000 (In Chinese).

39. Wang YX: Clinical observation of therapy with breviscapine injection on diabetic nephropathy. Zhong Wai Yi Liao 30: 126, 2011 (In Chinese).

40. Qian F: Clinical observation of therapeutic effects with breviscapine injection on 60 patients with diabetic nephropathy. An Mo Yu Kang Fu Yi Xue 2: 91-92, 2011 (In Chinese).

41. Li J: Observation of therapeutic effects with breviscapine injection and valsartan on early diabetic nephropathy. Zhongguo She Qu Yi Shi 12: 117, 2010 (In Chinese).

42. Wang W, Xing L, Wang CH and Li JC: Influence of breviscapine injection on hemorrheology and microcirculation of patients with diabetic nephropathy. Zhonghua Zhong Yi Yao Xue Hui 14: 963, 997, 2005 (In Chinese). 
43. Li J, Wu LY and Wang CY: Influence of breviscapine injection to correlated inflammatory cytokines in patients with type 2 early diabetic nephropathy. Zhong Yao Yao Li Yu Lin Chuang 27: 110-112, 2011 (In Chinese).

44. Zhao S: Observation of therapeutic effects with breviscapin on diabetic microalbuminuria. Guiyang Zhong Yi Xue Yuan Xue Bao 34: 37-38, 2012(In Chinese).

45. Liu YC: Observation of therapeutic effects with breviscapine on diabetic nephropathy. She Qu Zhong Yi Yao 10:76, 2008 (In Chinese).

46. Liu DK: Observation of therapeutic effects with breviscapin on hyperviscosity in diabetic nephropathy. Hubei Zhong Yi Za Zhi 25: 13-14, 2003(In Chinese).

47. Yuan CL and Yuan LY: Clinical observation of therapeutic effects with breviscapine on diabetic nephropathy. Shi Yong Tang Niao Bing Za Zhi 2:23, 2005(In Chinese).

48. Guo FH, Lv GY and Fan P: Clinical observation of therapy with valsartan and Dengzhanhuasu for diabetic nephropathy. Zhonghua Quan Ke Yi Xue 6: 895-896, 2008(In Chinese).

49. Huang GN, Chen JYand Zhang MY: Hemorrheology impact of treatment with breviscapine injection on diabetic nephropathy. Xin Zhong Yi 38: 34-35, 2006(In Chinese).

50. Cai HY. Clinical observation of treatment with breviscapin on 30 cases with early diabetic nephropathy. Dang Dai Yi Xue 15: 148, 2009(In Chinese).

51. Tabák AG, Herder C, Rathmann W, Brunner EJ, Kivimäki M Prediabetes: a high-risk state for diabetes development. Lancet 379:2279-2290, 2012.

52. Higgins GC and Coughlan MT: Mitochondrial dysfunction and mitophagy: The beginning and end to diabetic nephropathy? $\mathrm{Br} \mathrm{J}$ Pharmacol 171: 1917-1942, 2014.

53. Stanton RC: Clinical challenges in diagnosis and management of diabetic kidney disease. Am J Kidney Dis 63 (2 Suppl 2): S3-S21, 2014.

54. Badal SS and Danesh FR: New insights into molecular mechanisms of diabetic kidney disease. Am J Kidney Dis 63 (2 Suppl 2): S63-S83, 2014.
55. Mima A: Inflammation and oxidative stress in diabetic nephropathy: New insights on its inhibition as new therapeutic targets. J Diabetes Res 2013: 248563, 2013.

56. Xu XX, Zhang W, Zhang P, Qi XM, Wu YG and Shen JJ: Superior renoprotective effects of the combination of breviscapine with enalapril and its mechanism in diabetic rats. Phytomedicine 20: 820-827, 2013

57. Qi XM, Wu GZ, Wu YG, Lin H, Shen JJ and Lin SY: Renoprotective effect of breviscapine through suppression of renal macrophage recruitment in streptozotocin-induced diabetic rats. Nephron Exp Nephrol 104: e147-e157, 2006.

58. Zhao Y, Yang QP, Xiao H, Zhao C, Liu Hand Song DP: The effect of Erigeron breviscapus on apoptosis and expression of bax, bcl-2 in kidney of diabetic rats. Zhonghua Tang Niao Bing Za Zhi 17: 864-867, 2009 (In Chinese).

59. Wagener FA, Dekker D, Berden JH, Scharstuhl A and van der Vlag J: The role of reactive oxygen species in apoptosis of the diabetic kidney. Apoptosis 14: 1451-1458, 2009.

60. Chadban S, Howell M, Twigg S, Thomas M, Jerums G, Cass A, Campbell D, Nicholls K, Tong A, Mangos G, et al: The CARI guidelines. Assessment of kidney function in type 2 diabetes. Nephrology (Carlton) 15 (Suppl1): S146-S161, 2010.

61. Wang SH, Wang L, Zhou Y, Guo YJ, Yuan Y, Li FF, Huang Y and Xia WQ: Prevalence and control of dyslipidaemia among diabetic patients with microalbuminuria in a Chinese hospital. Diab Vasc Dis Res 10: 169-178, 2013.

62. Tomkin GH. Targets for intervention in dyslipidemia in diabetes. Diabetes Care 31 Suppl 2:S241-248, 2008.

63. Stadler K, Goldberg IJ, Susztak K. The evolving understanding of the contribution of lipid metabolism to diabetic kidney disease. Curr Diab Rep 15: 40, 2015.

64. Chen HC, Guh JY, Chang JM, Hsieh MC, Shin SJ and Lai YH: Role of lipid control in diabetic nephropathy. Kidney Int Suppl: S60-S62, 2005

65. Chen SC and Tseng CH: Dyslipidemia, kidney disease and cardiovascular disease in diabetic patients. Rev Diabet Stud 10: 88-100, 2013. 